\title{
LEAD LEVELS IN RETAIL SAMPLES OF SPANISH INFANT FORMULAE AND THEIR CONTRIBUTION TO DIETARY INTAKE OF INFANTS
}

\section{Navarro-Blasco I. and Alvarez-Galindo J.I.}

University of Navarra, Faculty of Sciences, Department of Chemistry, Pamplona (Navarra), E-31.080, Spain

Short title: Lead content of Spanish Infant Formulae

\section{Please, send all correspondence to:}

Dr. Iñigo Navarro-Blasco

Dpto. de Química y Edafología

Fac. de Ciencias

Universidad de Navarra

$\mathrm{C} /$ Irunlarrea $\mathrm{s} / \mathrm{n}$

31.080 Pamplona (Navarra)

Spain

Phone: +34 948425600

Fax: +34 948425649

E-mail: inavarro@unav.es 


\title{
Lead Levels in Retail Samples of Spanish Infant Formulae and Their Contribution to Dietary Intake Of Infants
}

\section{Navarro-Blasco I. and Alvarez-Galindo J.I.}

University of Navarra, Faculty of Sciences, Department of Chemistry, Pamplona (Navarra), E-31.080, Spain

\begin{abstract}
Lead concentrations in a total of 82 different types of infant formulae (cow's milk and soy based) marked in Spain were analysed by acid-microwave decomposition and anodic stripping voltammetry. Dietary lead intake from infant formula and tap water used for powder formula reconstitution were estimated in comparison with the provisional tolerable weekly intake (PTWI). Additionally, the influence of physical state (powder and ready to use formulae), the type of container used and the impact of industrial process from different manufacturers on lead levels were evaluated. According to our results, lead exposure from drinking water was negligible with respect to formulae investigated; where soya formulae contributed the highest intake (58 - 73 \% PTWI), non adapted starter and specialised formulae gave an moderate intake (31 - 42 and 26 - 37 \% PTWI, respectively) and, finally, pre-term, adapted starter and follow up formulae provided the lowest lead intake (22 - 25, 22 - 26 and 16 - 22 \% PTWI, respectively). Based on the current state of knowledge about lead toxicity, manufacturers are called to make an additional effort in order to keep a maximum lead level at $20 \mu \mathrm{g} \mathrm{l}^{-1}$ for all infant formulae, although it is recommendable that these formulations supply the upper limit $\left(5 \mu \mathrm{g} \mathrm{l^{-1 }}\right)$ of "normal" human milk.
\end{abstract}

Keywords: Lead, Infant formula, Anodic stripping voltammetry (ASV), Drinking water, Daily Intake, Provisional Tolerable Weekly Intake (PTWI). 


\section{Introduction}

When breast-feeding is discontinued, infant formula constitutes the main source of food for infants during the first months of life. Thus, these formulae have a special role in the diet of neonates because they should serve as substitutes for human milk. The need for essential micronutrients for adequate growth must be met by these formulae.

Over recent decades, different ingredients have been added to infant formulae, not only to better simulate the composition of breast milk, but also to impart health benefits. Raw material (cow's milk or isolated soy protein), processing methods, additives or mineral supplements and storage will in part determine the levels of minor and trace constituents present in the final product. Moreover, relatively low levels of toxic trace elements can only be expected to make an insignificant contribution to neonate dietary intake. The introduction of new formulations must pose no risk, or only minimal one.

Therefore, given the evident toxicological impact of lead on lactants, and considering that the absorption of this heavy element is significantly higher in infants than in adults (3-5 times greater), manufacturers have been acutely aware of the need to prevent any potential lead contamination (Patriarca et al. 2000). Consequently, it is desirable that infant formulae should be proportionally similar or inferior in lead levels to those found by human milk. In general, lead concentration in breast milk shows a marked variability depending on mothers' life style and dietary habits. Concentration levels found in literature from a pre-selected and well-identified population, suggest values of $2-5 \mu \mathrm{g} \mathrm{l^{-1 }}$ as the range of lead concentration to be expected in human milk and accepted as "normal" reference (WHO/IAEA 1989). However, it is more useful to consider a reference lead range of 3-26 $\mu \mathrm{g} \mathrm{l}^{-1}$ based on available literature data (Yang et al. 2003, Patriarca et al. 2000, Tripathi et al. 1999, Rodríguez et al. 1999, Ursinyova and Hladikova 1997, Coni et al. 1990, Dabeka et al. 1986).

The purpose of this survey was to determine the lead levels in a wide range of infant formulae from Spain and tap water from rural and urban areas in Navarra (Spain), to estimate the theoretical toxic intake from infant formula consumption as compared to the lower Provisional Tolerable Weekly Intake (PTWI), because of increased sensitivity of infants, expressed by the joint FAO/WHO Expert Committee on Food Additives (JECFA) and finally, to compare the metal content during processing and packaging among the different infant formula manufacturers (WHO 2000).

\section{Material and Methods}




\section{Collection and handling of samples}

Powdered $(n=61)$ and ready-to-use preparations $(n=14)$ infant formulae marketed in Spain by 9 different manufacturers were collected. Infant formula samples included soybased $(n=7)$ and based on cow's milk $(n=68)$ formulae. Different types of cow's milkbased formulae were classified as: pre-term formula $(n=7)$, starter formula (adapted, $n=$ 16 -formula for infants from the first day to 4-5 months of age, following the European Society for Paediatric Gastroenterology, Hepatology and Nutrition recommendations- and non adapted, $\mathrm{n}=4$-formula prepared for infants from birth to 12 months of age according to the American Academy of Pediatrics regulations-), follow-up formula ( $n=19)$ and specialised formula (hypoallergenic $(n=12)$, designed for lactose intolerant $(n=7)$, or inborn errors of metabolism $(n=10)$ formulae). Infant formula containers were stored in the dark at room temperature in a humidity controlled room. Special attention was given to the prevention of any contamination during sampling. Infant formula samples were opened in the clean laboratory within a laminar flow cabinet, using vinyl talc-free gloves (Rotiprotect $^{\circledR}$, Carl Roth, Karlsruhe, Germany) and plastic material (Plastibrand ${ }^{\circledR}$, Brand, Wertheim, Germany) previously cleaned in $5 \%$ nitric acid solution (Merck, Darmstadt, Germany) for six days and later rinsed three times with ultrapure water, to perform the sampling.

Tap water samples taken from thirty-nine points were collected in duplicate in the Community of Navarra (Spain), in both urban ( $\mathrm{n}=21$, in the provincial capital, Pamplona) and rural areas $(\mathrm{n}=18)$. A strict protocol was established to carry out tap water sampling. Water samples were collected in acid-washed 1-liter low density polyethylene containers and delivered to laboratory within 2-3 h. After sampling.

\section{Reagents}

Suprapure 65\% nitric acid (Merck, Darmstadt, Germany) was purified by sub-boiling distillation in a quartz distillation apparatus (Kürner, Rossenheim, Germany). All the water used for preparation and/or dilution of treated sample and standard solutions, was ultrapure deionised water type Milli Q. Acetate buffer solution was used as support electrolyte, prepared with $11.8 \mathrm{~mL}$ of suprapure $96 \%$ acetic acid, $3.7 \mathrm{~mL}$ of suprapure $25 \%$ amonium hydroxide (Merck, Darmstadt, Germany) filled up to $50 \mathrm{~mL}$ with ultrapure water.

\section{Sample treatment and mineralisation}

A closed, pressurized, high-microwave digestion unit (Milestone MLS 1200, Millestone s.r.l., Sorisole, Italy) equipped with a rotor for high pressure Teflon digestion vessels, was 
used for mineralisations of infant formula samples. Aliquots of infant formula (approximately, $0.3000 \mathrm{~g}$ powder, $1.500 \mathrm{ml}$ liquid) were weighed and mixed with $4 \mathrm{ml}$ of sub-boiling nitric acid. The microwave digestion program applied included several stages (250 W, 1 min.; 0 W, 1 min.; 250 W, 2 min; $400 \mathrm{~W} 2$ min ; and finally, $600 \mathrm{~W}, 1 \mathrm{~min}$.), followed immediately by ventilation (1 min.). Samples were digested in triplicate under the conditions optimised. Subsequently, an attack near dryness in hot plate with $1 \mathrm{~mL}$ suprapure 70\% percloric acid (Merck, Darmstadt, Germany) was performed in order to reach a complete ashing of the organic material. The residue was dissolved in ultrapure deionised water and then diluted up to $10 \mathrm{~mL}$. Solutions were kept stored frozen in precleaned polypropylene tubes at $-20{ }^{\circ} \mathrm{C}$ until analysis. Further details of sampling and treatment operations are described elsewhere (Navarro and Alvarez 2004).

With respect to drinking water treatment, measurement of $\mathrm{pH}$ was performed immediately upon receipt the water samples. Then, to avoid flocculation or losses by adsorption to the plastic walls, the samples were acidified with sub-boiling nitric acid ( $1 \mathrm{~mL}$ per litre) until approximately $\mathrm{pH}=2$. Aliquots of these solutions were stored refrigerated at $4{ }^{\circ} \mathrm{C}$ until analysis.

\section{Instrumental determination of trace elements}

Lead concentration was determined by anodic stripping voltammetry (ASV, Metrohm VA 646 processor and VA 647 stand, Herisau, Switzerland). A hanging mercury drop electrode (HMDE), a Pt auxiliary electrode and the reference electrode ( $\mathrm{Ag} / \mathrm{AgCl}$ in $3 \mathrm{M}$ $\mathrm{KCl}$ ) were used for all voltammetric measurements.

The digested infant formula solution ( $5 \mathrm{~mL}$ ) or tap water sample $(25 \mathrm{~mL})$, was placed in the electrochemical cell together with $5 \mathrm{~mL}$ of acetate buffer solution and deoxygenated with high-purity nitrogen (99.999\%) for $180 \mathrm{~s}$. A deposition potential of $-900 \mathrm{mV}$ was applied to a fresh mercury drop while the solution was stirred for 120 s. Following deposition, the solution was left to stand for $15 \mathrm{~s}$. The DPAS (differential pulse anodic stripping) voltammogram was recorded during the potential sweep from $-800 \mathrm{mV}$ to -350 $\mathrm{mV}\left(\mathrm{Pb}\right.$ half-wave potential $-456 \mathrm{mV}$ ) at a scan rate of $6.6 \mathrm{mV} \mathrm{s}^{-1}$ and pulse amplitude of $40 \mathrm{mV}$. Standard addition method was employed for measurements. A working standard solution containing $0.500 \mathrm{mg} \mathrm{l}^{-1}$ of lead from a stock $1000 \mathrm{mg} \mathrm{l}^{-1}$ standard solution (Merck, Darmstadt, Germany) was used. Three additions of working standard (10 $\mu \mathrm{L})$, purging with nitrogen while stirring for 20 s., were made to carry out the polarographic analysis. The values reported are the means of triplicate assays. 


\section{Quality Control}

With the goal of establishing analytical method reliability; blank reagents, aqueous internal standard and reference material were used to evaluate the quality assurance program.

Sample blanks for infant formula lead quantification, containing all reagents were carried through the entire analytical procedure. Detection limit (LOD) was calculated according to the definition and criteria established by IUPAC $\left(X_{b}+3 \sigma_{b}\right)$, as the average of three times the standard deviation of the reagent blank. Hence, when expressed in terms of infant formula, the LOD corresponds to $0.6 \mu \mathrm{g} \mathrm{l}^{-1}$ (wet weight, $\mathrm{n}=6$ ). Blank reagents in tap water analysis, consisting of ultrapure deionised water and reagents, were subjected to a similar sample preparation, storage and mixing with buffer solution, setting the LOD at $0.1 \mu \mathrm{g} \mathrm{l}^{-1}$.

An aqueous internal standard quality control containing $2.5 \mu \mathrm{g} \mathrm{l^{-1 }}$ of lead was previously measured to each batch of samples. Our findings $\left(2.40 \pm 0.2 \mu \mathrm{g} \mathrm{l}^{-1}\right.$, range $=2.2-2.6, \mathrm{n}=$ 34) showed good agreement, satisfying the criteria established in the quality program (2.2 $\left.-2.8 \mu \mathrm{g}^{-1}\right)$.

In order to test the accuracy of the analytical lead method, the IAEA-A11 milk powder (International Atomic Energy Agency) certified reference material was analysed. The obtained result (52.5 $\left.\pm 6.2 \mathrm{ng} \mathrm{g}^{-1}, \mathrm{n}=12\right)$ was in agreement with IAEA lead certified value (54 $\mathrm{ng} \mathrm{g}^{-1}$, confidence interval $29-79 \mathrm{ng} \mathrm{g}^{-1}$ ).

\section{Statistical Analysis}

Statistical analysis was performed using SPSS v.9.0 for Windows program.

\section{Results and Discussion}

\section{Lead levels in infant formula}

Table 1 summarises the lead concentrations for each of the different types of infant formulae investigated. Usually, levels of lead in formula are expressed in the literature in microgram per liter or kilogram on a ready to use basis. Because of the density of reconstituted infant formula is between $1.03-1.06 \mathrm{~g} \mathrm{ml}^{-1}$, concentrations reported in volume differ from weight given at most by 6 \% (Krachler et al. 1998).

[Insert table 1 about here] 
Wide variability in lead content observed by other authors is of special relevance. Consequently, median value is the most representative parameter to be used. The range of lead determined agrees reasonably well with most literature values (Ikem et al. 2002, Moreno-Rojas 2002, Tripathi et al. 1999, Rodríguez et al. 1999, Biego et al. 1998, Krachler et al. 1998, Ursinyova and Hladikova 1997, Esteve et al. 1994, Dabeka 1989, Dabeka and Mckenzie 1987,1988).

Non parametric Statistical Analyses (Kruskal-Wallis test) were performed with lead content for comparison of the different types of formulae, not establishing significant differences ( $p>0.05$ ). Therefore, it was not possible to pretend to classify in accordance with standard types, based on lead content.

However, lowest and highest lead values provided by premature and soya formulae respectively, stand out under halfway levels found in standard (starter and follow-up formulae) and special formulae analysed. In this sense, it is notorious the higher number of standard and premature formulae (9 from a total of 15) in which lead content are not detected; meaning that special care should be taken when cow's milk-based formulae are being produced, to avoid adventitious lead contamination from the manufacturing process.

Higher levels found in bulk cow's and isolate soy protein with similar variability than formula in lead content (McLaughlin et al. 1999) could point out the raw material as indicative of the potential contamination in milk-based and soya formulae, respectively. Infant formulae analysed are likely to be exposed to heavy metal contamination from raw material and added ingredients (calcium and phosphate salts, vitamins, other minerals and trace elements) rather than the contamination during processing or migration from container in which it is stored.

Moreover, taking into account that in previous works it was established that most of the intrinsic lead in bovine milk is associated mainly to casein (Mata et al. 1995), it seems appropriate to carry out the survey of lead levels in investigated formulae according to the main protein source contained (Table 2).

[Insert table 2 about here]

In spite of marked variability, there is evidence of lead increment normally associated with the milk fraction or protein type used in manufacturing. In standard cow's milk based formulas, the highest lead content is provided by those formulae based on whole milk $\left(6.21 \pm 11.28 \mu \mathrm{g} \mathrm{l}^{-1}\right)$, followed by skim-milk-based formulae (4.36 $\left.\pm 8.36 \mathrm{~g} \mathrm{~g}^{-1}\right)$ and lastly formulae that include whey proteins $\left(3.42 \pm 6.91 \mu \mathrm{g} \mathrm{l}^{-1}\right)$ or casein-based $\left(3.26 \pm 7.32 \mu \mathrm{g} \mathrm{l}^{-}\right.$ 
${ }^{1}$ ), as is expected owing to the higher degree of lead enrichment present in cow's milk. Current manufacturing policy is to reduce and replace the protein profile to be similar, as far as possible, to the pattern found in human milk. This fact could be of benefit to newer formulations richest in whey protein.

The high levels of lead in whey $\left(6.77 \pm 7.02 \mu \mathrm{g} \mathrm{l}^{-1}\right)$ and casein $\left(4.78 \pm 18.47 \mu \mathrm{g} \mathrm{l}^{-1}\right)$ hydrolysed formulae are a direct result of aggressive protein hydrolysis treatment, which provides lead enrichment in these formulations owing to chemicals and additives used.

The same consideration could be applied to the highest lead levels found in soya formulae $\left(9.59 \pm 19.58 \mu \mathrm{g} \mathrm{l}^{-1}\right)$ as a result of the o lead naturally present in soybeans and the complex isolation process (Dabeka and Mckenzie 1988).

In conclusion, apart from five formulae (hydrolised: 58.50 ; whole-milk-based: 37.10; skim-milk-based: 37.31 and soy-based: 55.24 and $28.90 \mu \mathrm{g} \mathrm{l}^{-1}$ ), most of the investigated formulae included in this survey, provide a lead concentration close to that expected to be found in the reference range of human milk reported in the literature (3-26 $\left.\mu \mathrm{g} \mathrm{l}^{-1}\right)$.

\section{Influence of physic state and container type}

Several surveys carried out with powder formulae collected between 1980 - 1985 (Dabeka 1989, Dabeka and Mckenzie 1987,1988) have shown significantly lower lead levels in glass-bottled formulas than in formulae sold in cans. In particular, initial results indicate that the major contributing factor to the presence of lead in the powder formulas was the container itself and not the formulae ingredients. Really, it seems that contamination caused by this potentially toxic element from the lead-soldered cans is gradually decreasing with the wider introduction of lacquered cans, lead-free solders or other kinds of recipients (aluminium bags).

In order to better understand the influence of the aggregation state on final lead level in formulae studied, we statistically evaluated the lead content in both powder and ready-touse liquid formulae. Lead concentration found in 14 different formulae marked in both forms did not differ significantly ( $p>0.05$, Wilcoxon's test), indicating that the most important factor of lead levels was the formula ingredients. Furthermore, results summarised in table 3 show a tendency of ready-to-use formula to have only slightly higher lead levels than powder formulae. Additionally, general lead levels in aluminium sealed bags $\left(\mathrm{n}=19,2.90 \pm 5.47 \mu \mathrm{g} \mathrm{l}^{-1}\right)$ and tetrabrick $\left(\mathrm{n}=7,7.25 \pm 3.70 \mu \mathrm{g} \mathrm{l}^{-1}\right)$ formulae were consistently lower than those commercialised in cans $\left(\mathrm{n}=49,5.46 \pm 12.60 \mu \mathrm{g} \mathrm{l}^{-1}\right)$ or glass $\left(\mathrm{n}=7,10.63 \pm 12.37 \mu \mathrm{g} \mathrm{l}^{-1}\right)$, respectively. 
[Insert table 3 about here]

\section{Impact on lead levels from different manufacturers}

Nine different manufacturers provide the most infant formulae sold in Spain. Box diagrams of lead concentration distribution for all formulae commercialised by each manufacturer are shown in figure 1.

\section{[Insert figure 1 about here]}

A comparison of statistically significant differences (one factor Anova, $\mathrm{p}=0.012$ ) between the commercial brands was performed. Globally, lead level provide by the manufacturer 7 ( $\mathrm{n}=5,18.12 \pm 18.76 \mu \mathrm{g} \mathrm{l}^{-1}$ ) was significantly higher (Mann Whitney U-test, $\mathrm{p}<0.034$ ) than those from most of the other brands. Manufactures 2, 4 and 8 were classified at an intermediate level with $7.32 \pm 6.69(n=14), 7.99 \pm 8.71(n=3)$ and $7.10 \pm 14.96(n=16)$ $\mu \mathrm{g} \mathrm{l}^{-1}$, respectively. Manufacturers $5\left(1.77 \pm 1.92 \mu \mathrm{g} \mathrm{l}^{-1} ; \mathrm{n}=11\right)$ and $1\left(3.38 \pm 3.14 \mu \mathrm{g} \mathrm{l}^{-1} ; \mathrm{n}\right.$ $=16$ ) were discovered had the lowest lead concentration.

Most manufacturers observed an adequate and relatively narrow range of lead concentration, highlighting the meticulous care taken in their industrial handling process of infant formulae, with the exception of two commercial brands (manufacturers 3 and 6).

In view of these results and taking into account the lead range assumed as reference where low and high quartile reported from available literature data have been selected, it seems reasonable to set the same limits for infant formula. Thus, the lead value of $26 \mu \mathrm{g} \mathrm{l}^{-1}$ for infant formulas in a unique distribution corresponds to percentile 93; that is, only 5 infant formula of a total of 82, exceed this upper limit. Therefore, manufactures should strive to improve and control until at least the upper value is set. Next step would be ensure in infant formulae, the concentration level expected for lead in human milk under "usual" conditions, after exclusion of extreme data $\left(2-5 \mu \mathrm{g} \mathrm{l}^{-1}\right)$, just as any manufacturers are already doing.

\section{Estimated dietary lead intake}

Lead concentration determined in the different types of formulae were used to calculate daily and weekly dietary lead intake by infants on the basis of feeding tables provided by manufacturers, under the assumption that they receive only formulae.

The estimated daily intake amount of lead supplied by the infant formulae analysed are shown in table 4. Literature values of lead daily dietary intake (Dabeka, 1989: $13.2 \mu$ day $^{-}$ 
1, WHO/OIEA, 1989: < 0.5 - $19 \mu \mathrm{g} \mathrm{day}^{-1}$, Coni et al. 1990: 2.6 - 17.6, Rodríguez et al. 1999: 0.08 - $24.25 \mu$ day $^{-1}$ and Ursinyova and Hladikova, 1997: $<0.38-19.6 \mu$ g day $^{-1}$ ) are similar or slighty higher than the calculated intake $\left(2.4-20.8 \mu \mathrm{g} \mathrm{day}^{-1}\right)$ by means of a human milk reference working range, assuming a daily milk intake of $200 \mathrm{ml} \mathrm{kg}^{-1}$ b.w.

[Insert table 4 about here]

However it should be kept in mind that lead levels in human milk are widely variable and may lead to daily intake by breast-fed infant exceeding the Provisional Tolerable Weekly Intake for lead of $25 \mu \mathrm{g} \mathrm{kg}^{-1}$ b.w. In this sense, daily lead intake calculated $(1.6-4.0 \mu \mathrm{g}$ day $^{-1}$ or $0.36-0.89 \mu \mathrm{g} \mathrm{kg}^{-1}$ day $^{-1}$ ) from usual human milk values is the most appropriate criterion to be observed in order to compare intakes for infants fed on formulae.

Thus, excluding special or soya formulae, in general even though standard infant formulae provide a low lead intake, it still remain a somewhat higher than the intake of human milk.

Moreover, lead intake depends on both recommended doses and the feeding tables, and generally increases with the age of the infant. Figure 2 shows the weekly lead intake (percentage of PTWI) estimated for each type of infant formulae studied according to lactation stage.

\section{[Insert figure 2 about here]}

Undoubtedly, soya formulae contributed the highest intake (58 - $73 \%$ ), nearly twice as much as other formula; non adapted starter and specialised formula gave an intermediate intake (31 - 42 and 26 - $37 \%$, respectively) and, finally, adapted starter and follow up formulae provided the lowest lead intake (22 - 26 and $16-22 \%$, respectively).

Given the evident impact of lead on premature infants, considering that the absorption and retention of lead by immature infants is significantly higher than adults, lower standard for permissible lead exposure should be adopted. Figure 3 compares the weekly lead intake of infants fed on premature formulae and breast milk with the value of PTWI calculated according to body weight.

\section{[Insert figure 3 about here]}

These formulae provide a lead intake (22 - $25 \%$ ) similar to standard formulas. Besides, it is relatively lower than that supplied by Spanish human milk (Rodríguez et al. 1999) and fortunately, closer and far greater than that provided by the lower and upper limit of human milk levels, respectively. As mentioned above, and as seen in figure 3, extreme lead values 
available in literature could represent a significant source of lead exposure for breast-fed infants.

Finally, to obtain a global perspective, it is possible to evaluate the hypothetical lead concentration which a formula may contain to provide a potential risk intake which exceeds lead ISTP value. This limit value range from 20.2 to $25.8 \mu \mathrm{g} \mathrm{l}^{-1}$, assuming an ordinary feeding regimen and using the doses recommended by manufacturers. This fact increases the suspicious group in three more, so lead content in eight specific formulae is called into question where intake supplies may reach up to at least 90.8 - $249.9 \%$ PTWI (evaluated from lower and higher lead content in this controversial group of infant formulae, respectively).

\section{Drinking water lead levels and its contribution to dietary intake}

Tap water is a recognised but often overlooked as a significant potential source of lead. This heavy element is present in drinking water to a certain extent as a result of its dissolution from natural sources but primarily from house plumbing systems (WHO 1996).

Both WHO guidelines (WHO 1996) and European Community legislation (Commission of the European Communities 1998) have established the specifications for drinking water quality intended for human consumption, setting out the lead concentration of $10 \mu \mathrm{g} \mathrm{l}^{-1}$. In part, this level was established as a result of studies of lead accumulation and balance in infants (WHO 2000).

The level of lead in drinking water samples collected in this survey was $0.4 \pm 1.1 \mu \mathrm{g} \mathrm{l}^{-1}$, with a $\mathrm{pH}$ range of $7.4-8.3$, those alkaline values reduce the corrosion of plumbing systems and hence, avoid the infant's lead intoxication occurring when formulae is reconstituted in contaminated water (Baum and Shannon 1997).

The lead content found in rural areas $\left(0.2 \pm 0.5 \mu \mathrm{g}^{-1}\right.$, range $\left.<0.10-9.0 \mu \mathrm{g} \mathrm{l^{-1 }}\right)$ is a little lower than in the urban area of Pamplona $\left(0.7 \pm 1.9 \mu \mathrm{g}^{-1}\right.$, range $\left.<0.10-38.3 \mu \mathrm{g}^{-1}\right)$. However, lead levels above guideline value were detected in three sampling points at concentrations of 10.9, 14.4 and $38.3 \mu \mathrm{g} \mathrm{l}^{-1}$.

The prevention of lead poisoning by bottle-fed infants requires the establishment, in numerical terms, of the real values of potential impact (Gulson et al. 1997). Ziegler et al. (1978) described that positive lead balance appear when daily lead intake reaches $5 \mu \mathrm{gg}^{-1}$ of body weight and greater intakes will develop a lead burden. On the basis of feeding tables for infant formula reconstitution, a lead level in tap water between $28.3-41.7 \mu \mathrm{g} \mathrm{l}^{-1}$, 
depends on sex and lactation period, may contribute by itself to an infant's lead burden. One tap water sample revealed lead contamination, probably caused by antiquated plumbing system of this sampling point.

Assuming the median value found in this study, the influence of lead content in tap water by itself, is negligible with respect to the total lead concentration supplies by formulae investigated (table 4), approximately $1.8-2.2 \%$ of the PTWI. Nevertheless, this assertion must be interpreted carefully, since lead level in drinking water is highly variable and depends on several factors, which could be minimised taking measures such as the removal of lead pipes and the adjustment of the $\mathrm{pH}$ in the distribution system to increase alkalinity; and failing that, to avoid the first-draw morning water.

\section{Conclusions}

International organisms and nutritional committees assess infant formula, drinking water and dust or soil as the main potential sources of infant lead exposure (WHO 2000). Infants are more susceptible to the toxic action of lead where the impact on health might be anticipated from reducing dietary exposure.

Our findings suggest that lead levels found in this work are similar or lower to data reported from actual or older surveys. This fact indicates that infant formula manufacturers have achieved substantial reductions of lead levels, presumably through more careful selection of raw material and/or avoidance of contamination during industrial processing. However, based on the current state of knowledge on lead infant toxicity, considering infants as the most sensitive group of population, manufacturers should take steps to keep a maximum lead value at $20 \mu \mathrm{g} \mathrm{l}^{-1}$ for all infant formulae, although it is desirable that these formulations supply the upper limit (5 $\left.\mu \mathrm{g}^{-1}\right)$ of "normal” human milk.

Finally, from a research standpoint, the experimental results have shown that there are significant variations of lead levels across the infant formula brands. This could be attributed to different manufacturing practices, variation in quality of raw material, finished product and packaging container used by infant formula manufacturer. Thus, speciation studies are required in the future to characterise lead chemical forms present in infant formula (Brätter et al. 1998), with the aim of evaluating the safety of adding any new ingredient or change in the handling of infant formulae.

\section{References}


Baum, C. R., and Shannon, M. W., 1997, The lead concentration of reconstituted infant formula. Clinical Toxicology, 35, 371-375.

Biego, G. H., Joyeux, M., Hartemann, P., and Debry, G., 1998, Determination of mineral contents in different kinds of milk and estimation of dietary intake in infants. Food Additives and Contaminants, 15, 775-781.

Brätter, P., Navarro, I., Negretti de Brätter, V., and Raab, A., 1998, Speciation as an analytical aid in trace element research in infant nutrition. Analyst,123, 821-826.

Commission of the European Communities, 1998, Council Directive of 3 November 1998 on the quality of water intended for human consumption (98/83/EC). Official Journal of European Communities Legislation, L330, 32-54.

Coni, E., Falconieri, P., Ferrante, E., Semeraro, P., Beccaloni, E., Stacchini, A., and Caroli, S., 1990, Reference values for essential and toxic elements in human milk. Annali dell'Istituto Superiore di Sanità, 26, 119-130.

Dabeka, R. W., 1989, Survey of lead, cadmium, cobalt and nickel levels in infant formulas and evaporated milks and estimation of dietary intakes of the elements by infants 0 12 months old. The Science of the Total Environment, 89, 279-289.

Dabeka, R. W., and Mckenzie, A. D., 1987, Lead, cadmium and fluoride levels in marked milk and infant formulas in Canada. Journal of Association of Official Analytical Chemists, 70, 754-757.

Dabeka, R. W., and Mckenzie, A. D., 1988, Lead and cadmium levels in commercial infant formulas and dietary intake by infants 0-1 year old. Food Additives and Contaminants, 5, 333-342.

Dabeka, R. W., Karpinski, K. F., Mckenzie, A. D., and Bajdik, C. D., 1986, Survey of lead, cadmium and fluoride in human milk and correlation of levels with environmental and food factors. Food and Chemical Toxicology, 24, 913-921.

Esteve, M. J., Farré, R., and Frigola, A., 1994, Determination of Cd, Cu, Pb and Zn content of infant formulas by differential pulse anodic stipping voltammetry (DPASV). Die Nahrung, 38, 386-392.

Gulson, B. L., James, M., Giblin, A. M., Sheehan, A., and Mitchell, P., 1997, Maintenance of elevated lead levels in drinking water from occasional use and potential impact on blood leads in children. The Science of the Total Environment, 205, 271-275. 
Ikem, A., Nwankwoala, A., Odueyungbo, S., Nyavor, K., and Egiebor, N., 2002, Levels of 26 elements in infant formula from USA, UK, and Nigeria by microwave digestion and ICP-OES. Food Chemistry, 77, 439-447.

Krachler, M., Rossipal, E., and Irgolic, K. J., 1998, Trace elements in formulas based on cow and soy milk and in Australian cow milk determined by inductively coupled plasma mass spectrometry. Biological Trace Element Research, 65: 53-74.

Mata, L., Sánchez, L., Puyol, P. and Calvo, M., 1995, Changes in distribution of cadmium and lead in human and bovine milk induced by heating or freezing. Journal of Food Protection, 59, 46-50.

McLaughlin, M. J., Parker, D. R., and Clarke, J. M., 1999, Metals and micronutrients food safety issues. Field Crops Research, 60, 143-163.

Moreno-Rojas, R., Sánchez-Segarra, P. J., Cañal-Ruiz, C., Amaro-López, M. A., and Zurera-Cosano, G., 2002, Lead content in Spanish marked infant formulas and toxicological contribution. Food Additives and Contaminants, 19, 241-245.

Navarro, I., and Alvarez, J.I., 2004, Selenium content of Spanish infant formula and human milk: Influence of protein matrix, interactions with other trace elements and estimation of dietary intake by infants. Journal of Trace Elements in Medicine and Biology, 17, 277-289.

Patriarca, M., Menditto, A., Rosi, B. Lyon, T. D. B., and Fell, G. S., 2000, Environmental exposure to metals of newborns, infants and young children. Microchemical Journal, 67, 351-361.

Rodríguez, E. M., Delgado, E., and Díaz, C., 1999, Concentrations of cadmium and lead in in different types of milk. Z Lebensm Unters Forsch, 208, 162-168.

Tripathi, R. M., Raghunath, R., Sastry, V. N., and Krishanamoorthy, T. M., 1999, Daily intake of heavy metals by infants through milk and milk products. The Science of the Total Environment, 227, 229-235.

Ursínyová, M., and Hladíková, V., 1997, The intake of selected toxic elements from milk in infants. Fresenius Environment Bulletin, 6, 627-632.

WHO. World Health Organization, 1996, Lead. Guidelines for drinking-water quality, vol. 2. Health criteria and other supporting information, $2^{\text {nd }}$ edition (Geneva: World Health Organization), pp. 254-275. 
WHO. World Health Organization, 2000, Safety evaluation of certain food additives and contaminants: Fifty-third report of the Joint FAO/WHO Expert Committee on Food Additives. WHO Food Additives Series, 44. (Geneva: WHO).

WHO/IAEA. World Health Organization and International Atomic Energy Organization, 1989, Minor and trace elements in breast milk. (Geneva: WHO).

Yang, L., Zhang, M., Lin, S., Chen, D., and Zheng, M., 2003, Minor and trace element analysis in breast milk using inductively coupled plasma mass spectrometry (ICPMS). Microchimica Acta, 142, 85-88.

Ziegler, E. E., Edwards, B. B., Jensen, R.L., Mahaffey, K. R., and Fomon, S. J., 1978, Absorption and retention of lead by infants. Pediatric Research, 12, 29-34. 
Table 1. Lead concentrations in different types of infant formulae investigated $\left(\mu g \mathrm{l}^{-1}\right)$.

\begin{tabular}{|l||cccc||}
\hline \multicolumn{1}{|c||}{ Infant formula } & n.d. & Median \pm SD & Range \\
\hline \hline $\begin{array}{l}\text { Preterm Formula } \\
\text { Starter Formula }\end{array}$ & 7 & 1 & $2.57 \pm 6.21$ & $<$ LOD -17.24 \\
$\quad$ - Non adapted & 4 & - & $7.99 \pm 4.99$ & $3.39-14.96$ \\
$\quad$ - Adapted & 16 & 5 & $5.53 \pm 10.23$ & $<$ LOD -37.10 \\
Follow-up Formula & 19 & 3 & $5.33 \pm 8.68$ & $<$ LOD -33.31 \\
Specialised Formula & & & & \\
$\quad$ - Without lactose Formula & 7 & 2 & $5.85 \pm 8.18$ & $<$ LOD -21.25 \\
$\quad$ - Hypoallergenic Formula & 12 & 2 & $5.43 \pm 6.18$ & $<$ LOD -22.32 \\
$\quad$ - Inborn errors diet & 10 & 1 & $5.67 \pm 17.24$ & $<$ LOD -58.50 \\
Soya Formula & 7 & 1 & $9.59 \pm 19.58$ & $<$ LOD -55.24 \\
\hline
\end{tabular}

n.d.: number of samples non detected

LOD: Detection limit 
Table 2. Lead content in infant formulae according to the main protein contained $\left(\mu \mathrm{g} \mathrm{l}^{-1}\right)$.

\begin{tabular}{||l||c|c|c||}
\hline \multicolumn{1}{||c||}{ Infant formula } & \multicolumn{1}{c|}{$n$} & \multicolumn{1}{c|}{ Median \pm SD } & \multicolumn{1}{c|}{ Range } \\
\hline \hline Whey-based & 14 & $3.42 \pm 6.91$ & $<\mathrm{LOD}-21.85$ \\
\hline Casein-based & 10 & $3.26 \pm 7.32$ & $<\mathrm{LOD}-21.25$ \\
\hline Skim-milk-based & 20 & $4.36 \pm 8.36$ & $<\mathrm{LOD}-33.31$ \\
\hline Whole-milk-based & 11 & $6.21 \pm 11.28$ & $<\mathrm{LOD}-37.10$ \\
\hline Whey hydrolysed & 8 & $6.77 \pm 7.02$ & $<\mathrm{LOD}-22.32$ \\
\hline Casein hydrolysed & 9 & $4.78 \pm 18.47$ & $<\mathrm{LOD}-58.50$ \\
\hline Free aminoacids & 2 & $4.53 \pm 4.73$ & $1.19-7.88$ \\
\hline No protein & 1 & 4.28 & - \\
\hline Soy-based & 7 & $9.59 \pm 19.58$ & $<\mathrm{LOD}-55.24$ \\
\hline
\end{tabular}

LOD: Detection limit 
Table 3. Lead levels ( $\mu \mathrm{g}^{-1}$ ) from different types of infant formulae studied attending to aggregation state (powder or liquid formulae).

\begin{tabular}{|c|c|c|c|c|c|c|}
\hline \multirow{2}{*}{ Formula } & \multicolumn{3}{|c|}{ Powder } & \multicolumn{3}{|c|}{ Ready-to-use } \\
\hline & $n$ & Median & Range & $n$ & Median & Range \\
\hline Preterm Formula & 6 & $2.22 \pm 6.32$ & $<$ LOD - 17.24 & 1 & 10.5 & - \\
\hline $\begin{array}{l}\text { Starter Formula } \\
\text { Non adapted } \\
\text { Adapted } \\
\end{array}$ & $\begin{array}{l}3 \\
12\end{array}$ & $\begin{array}{l}6.21 \pm 6.03 \\
2.32 \pm 7.43 \\
\end{array}$ & 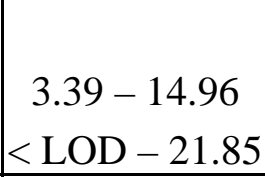 & $\begin{array}{l}1 \\
4 \\
\end{array}$ & $\begin{array}{c}9.8 \\
11.55 \pm 14.93 \\
\end{array}$ & $\begin{array}{c}- \\
3.42-37.10 \\
\end{array}$ \\
\hline Follow-up Formula & 13 & $5.33 \pm 9.60$ & $<$ LOD - 33.31 & 6 & $5.20 \pm 7.00$ & $1.02-19.68$ \\
\hline $\begin{array}{c}\text { Specialised Formula } \\
\text { Hypoallergenic }\end{array}$ & 10 & $5.43 \pm 6.54$ & $<$ LOD - 22.32 & 2 & $3.87 \pm 5.00$ & $<\mathrm{LOD}-7.41$ \\
\hline Total & 68 & $5.07 \pm 11.25$ & $<$ LOD - 58.50 & 14 & $7.70 \pm 9.62$ & $<\mathrm{LOD}-37.10$ \\
\hline
\end{tabular}

LOD: Detection limit 
Table 4. Daily intakes of lead for infants fed on infant formulae and drinking water used in the reconstitution of powder formulae $\left(\mu \mathrm{g} \mathrm{day}^{-1}\right)$.

\begin{tabular}{|c|c|c|c|c|c|c|c|c|}
\hline \multirow[b]{2}{*}{ Age } & \multicolumn{2}{|c|}{ Starter Formula } & \multirow{2}{*}{$\begin{array}{c}\text { Follow-up } \\
\text { Formula }\end{array}$} & \multicolumn{3}{|c|}{ Specialised Formula } & \multirow{2}{*}{$\begin{array}{c}\text { Soya } \\
\text { Formula }\end{array}$} & \multirow{2}{*}{$\begin{array}{c}\text { Drinking } \\
\text { water }\end{array}$} \\
\hline & $\begin{array}{c}\text { Non } \\
\text { adapted }\end{array}$ & Adapted & & $\begin{array}{l}\text { Without } \\
\text { lactose }\end{array}$ & HA & $\begin{array}{c}\text { Inborn } \\
\text { errors } \\
\text { diet } \\
\end{array}$ & & \\
\hline 0 - 2 weeks & 5.4 & 3.2 & - & 4.5 & 4.0 & 3.7 & 8.8 & 0.23 \\
\hline 3 - 4 weeks & 6.4 & 4.2 & - & 6.0 & 5.1 & 4.9 & 11.4 & 0.31 \\
\hline 2 month & 8.2 & 4.9 & - & 7.1 & 5.7 & 6.2 & 14.0 & 0.39 \\
\hline 3 month & 8.2 & 5.7 & - & 7.6 & 6.5 & 7.2 & 14.9 & 0.39 \\
\hline 4 - 5 month & 10.2 & 6.4 & 6.1 & 8.8 & 7.8 & 8.2 & 17.8 & 0.45 \\
\hline 6 month & 9.0 & 6.2 & 5.5 & 8.7 & 7.8 & 8.2 & 16.4 & 0.41 \\
\hline$>7$ month & - & - & 5.1 & - & - & - & - & 0.27 \\
\hline
\end{tabular}




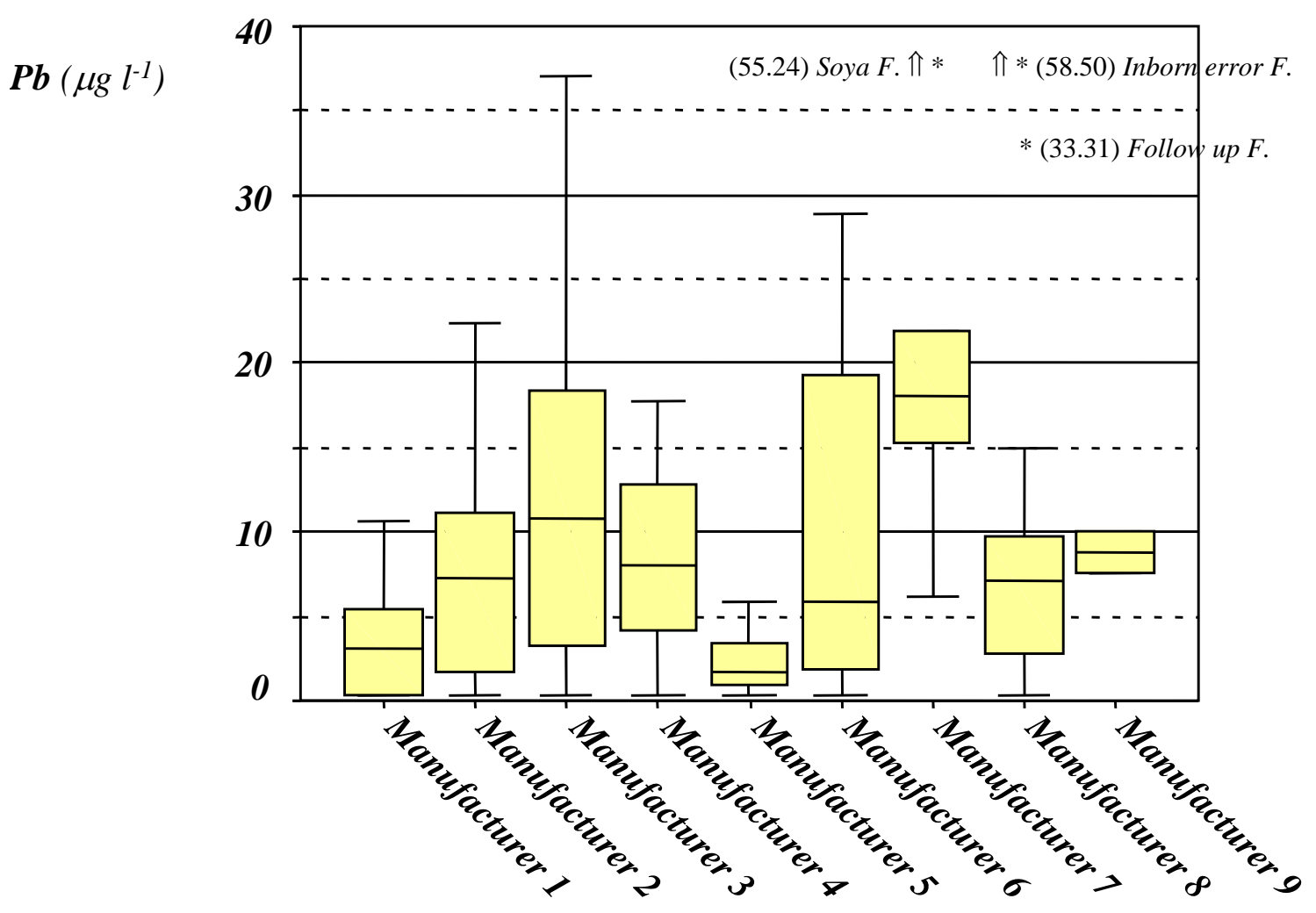




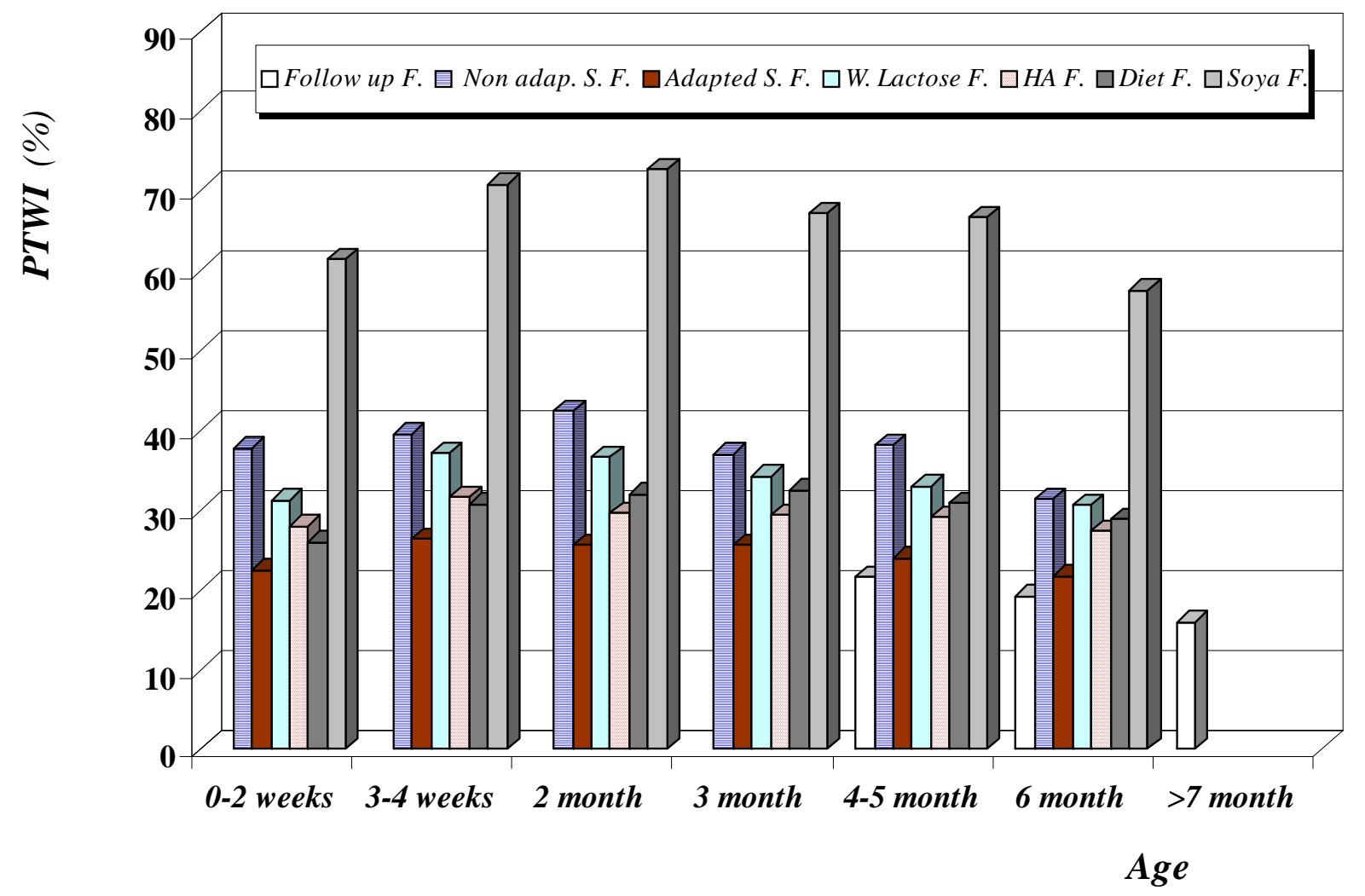




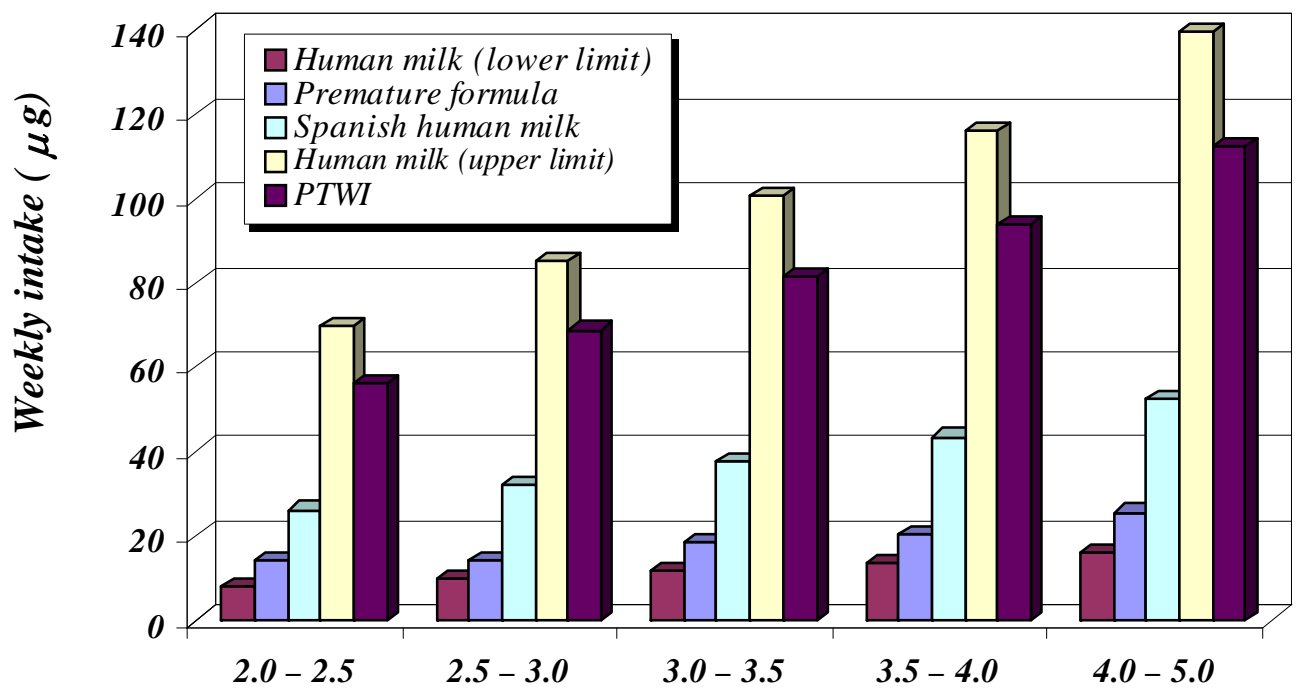

Body weight (kg) 
Figure 1. Lead distributions in infant formulae provided by different manufacturers ( $\mu g \mathrm{l}^{-}$ 1)

Figure 2. Percentages of PTWI for lead estimated from infant formulae.

Figure 3. Weekly dietary lead intake for infant fed on premature infant formulae and human milk ( $\mu$ g week $\left.{ }^{-1}\right)$. 


\section{Acknowledgements}

Authors wish to thank to Departamento de Industria y Tecnología, Comercio, Turismo y Trabajo (Gobierno de Navarra) and Plan de Investigación de la Universidad de Navarra (PIUNA) for financial support. 